\title{
FORMAÇÃO DE BIOFILMES BACTERIANOS EM DIFERENTES SUPERFÍCIES DE INDÚSTRIAS DE ALIMENTOS
}

\section{Bacterial biofilm formation in different surfaces of food industries}

\author{
Karine Angélica Dalla Costa ${ }^{1 *}$, Mariane Ferenz ${ }^{2}$, Sheila Mello da Silveira ${ }^{2}$, \\ Alessandra Farias Millezi ${ }^{2}$
}

\begin{abstract}
RESUMO
O termo biofilme descreve a forma de vida microbiana séssil, caracterizada pela adesão de microrganismos a alguma superfície e com a produção de substâncias poliméricas extracelulares. Nas indústrias de alimentos, a formação de biofilmes resulta em graves problemas, já que pode ser fonte de contaminação do alimento, comprometendo a qualidade final do produto e a saúde do consumidor. O objetivo deste trabalho foi verificar a adesão de biofilmes (células sésseis) de bactérias patogênicas e/ou deteriorantes sobre superfícies da indústria alimentícia. As espécies bacterianas testadas foram Pseudomonas aeruginosa ATCC 27853, Staphylococcus aureus ATCC 29213, Listeria monocytogenes ATCC 19117 e Salmonella Typhimurium ATCC 14028. Utilizaram-se cupons de aço inoxidável e polipropileno como superfícies de contato. Os resultados demonstraram que $P$. aeruginosa e $S$. Typhimurium apresentaram maior capacidade de formação de biofilme. Estatisticamente, não houve diferença nas contagens das células de $P$. aeruginosa e $S$. Typhimurium ( $\mathrm{p}>0,05)$, o mesmo ocorreu entre L. monocytogenes e $S$. aureus. Entretanto, as contagens de células de $P$. aeruginosa e $S$. Typhimurium foram estatisticamente maiores que $S$. aureus e L. monocytogenes $(\mathrm{p}<0,05)$. Através da microscopia eletrônica de varredura constatou-se também maior adesão de $P$. aeruginosa. Os resultados obtidos demonstraram que dentre as espécies bacterianas testadas $P$. aeruginosa foi a bactéria com maior capacidade de formação de biofilme.

Palavras-chave: bactéria patogênica; adesão microbiana; aço inoxidável; polipropileno; qualidade do produto.
\end{abstract}

1 Universidade Regional Integrada do Alto Uruguai e das Missões (URI), Av. Sete de Setembro, 1621, Fátima, 99709-510, Erechim, RS, Brasil. E-mail: karinedallacosta@hotmail.com

2 Instituto Federal Catarinense, Concórdia, SC, Brasil.

* Autor para correspondência.

Recebido / Received: 16/08/2016

Aprovado / Approved: 24/01/2017 


\begin{abstract}
The term biofilm describes the sessile microbial life form, characterized by microorganism adhesion to any surface and with the production of extracellular polymeric substances. In food industries, the formation of biofilms results in serious problems, since it can be a contamination source of the food product, compromising the final product quality and consumer health. The aim of this study was to verify the adhesion of biofilms (sessile cells) of pathogenic and/or deteriorating bacteria against surfaces of the food industry. The bacterial species tested were Pseudomonas aeruginosa ATCC 27853, Staphylococcus aureus ATCC 29213, Listeria monocytogenes ATCC 19117 and Salmonella Typhimurium ATCC 14028. It was used stainless steel and polypropylene coupons as contact surfaces. The results demonstrated that $P$. aeruginos $a$ and $S$. Typhimurium showed higher biofilm formation capacity. Statistically, there was no difference in count of $P$. aeruginosa and $S$. Typhimurium $(\mathrm{p}>0.05)$ cells. The same occurred between $L$. monocytogenes and $S$. aureus. However, the counts of $P$. aeruginosa and $S$. Typhimurium cells were statistically higher than $S$. aureus and L. monocytogenes $(\mathrm{p}<0.05)$. By means of scanning electron microscopy it was also found increased adhesion of $P$. aeruginosa. The results revealed that $P$. aeruginosa was the bacterial species with higher biofilm formation capacity among the others.
\end{abstract}

Keywords: pathogenic bacteria; microbial adhesion; stainless steel; polypropylene; product quality.

\section{INTRODUÇÃO}

A formação do biofilme ocorre por uma série de eventos sequenciais, em que a adesão inicial de bactérias planctônicas à superfície (processo reversível) é seguida por subsequente proliferação e acúmulo de camadas de células e, finalmente, pela formação da comunidade microbiana (processo irreversível), embebida em matriz de exopolissacarídeo produzida por si mesma (CAIXETA, 2008).

O biofilme pode ser formado por populações desenvolvidas a partir de uma única ou de múltiplas espécies, ou seja, quando o biofilme é composto por espécies heterogêneas, os produtos metabolizados por uma espécie podem servir de suporte para o crescimento de outras, enquanto a adesão de algumas espécies pode fornecer ligantes que promovem a ligação de outras (DUNNE JÚNIOR, 2002). Por outro lado, a competição por nutrientes e o acúmulo de produtos tóxicos produzidos pelos colonizadores primários, podem limitar a diversidade de espécies no interior do biofilme (CAIXETA, 2008).

A adesão e formação de biofilmes são limitadas por características do microrganismo, do material aderente e do meio envolvendo o microrganismo, como o $\mathrm{pH}$, temperatura, tempo de agitação e uma variedade de outros fatores (CAIXETA, 2008).

Dentre os microrganismos que podem participar de processos de adesão e podem gerar problemas de saúde pública ou de ordem econômica, ressalta-se: Pseudomonas aeruginosa, Pseudomonas fragi, Pseudomonas fluorescens, Micrococcus sp. e Enterococcus faecium. Como exemplos de patógenos pode-se citar: Listeria monocytogenes, Yersinia enterocolitica, Salmonella Typhimurium, Escherichia coli O157:H7, Staphylococcus aureus e Bacilluscereus (CRIADO et al., 
1994; LERICHE; CARPENTIER, 1995; SMITH; FRATÂMICO, 1995; ANDRADE et al., 1998; PARIZZI et al., 2004).

Sabe-se que nenhum dos materiais normalmente empregados na indústria de alimentos apresenta capacidade de impedir os processos iniciais de formação do biofilme, bem como o desenvolvimento de seu ciclo (KINGSHOTT et al., 2003). Segundo Mah; O'Toole (2001), os microrganismos quando em biofilme têm sua fisiologia modificada, tornando-se mais resistentes.

Nas indústrias de alimentos, a formação de biofilme microbiano na superfície de equipamentos e utensílios usados no processamento dos alimentos, resulta em graves problemas já que pode ser fonte de contaminação do alimento, comprometendo a qualidade final do produto e a saúde do consumidor (MILLEZI et al., 2012). Sabese que, após limpeza e desinfecção das superfícies, se a matriz exopolissacarídea não for removida completamente, bactérias aderem-se com maior facilidade, formando biofilme (KIVES et al., 2006) e sendo esta fonte potencial na contaminação de produtos processados (SHARMA; ANAND, 2002).

Desta maneira é necessário primeiramente verificar a capacidade de formação de biofilmes das bactérias em diferentes superfícies, para posteriormente buscar métodos a fim de evitar ou erradicar tais comunidades.

O objetivo deste estudo, foi analisar a formação de biofilmes por bactérias patogênicas e/ou deteriorantes sobre superfícies utilizadas em estabelecimentos que produzem, comercializam e/ou industrializam alimentos. Desta forma, detectou-se a formação de biofilme de Pseudomonas aeruginosa ATCC 27853, Staphylococcus aureus ATCC 29213, Listeria monocytogenes ATCC 19117 e Salmonella Typhimurium ATCC 14028 em condições laboratoriais similares às encontradas na indústria de alimentos, utilizando o aço inoxidável AISI 304 e o polipropileno como superfícies de contato.

\section{MATERIAL E MÉTODOS}

Todas as etapas deste estudo foram realizadas no laboratório de Microbiologia de Alimentos, localizado no Instituto Federal Catarinense (IFC) de Concórdia, $\mathrm{SC}$, com exceção da microscopia eletrônica de varredura, a qual foi realizada na Universidade Federal de Lavras (UFLA), MG. As cepas bacterianas utilizadas neste estudo foram Listeria monocytogenes ATCC 19117, Pseudomonas aeruginosa ATCC 27853, Staphylococcus aureus ATCC 29213 e Salmonella Typhimurium ATCC 14028. Cupons de aço inoxidável AISI 304 e polipropileno (ambos no tamanho de $20 \times 8$ x $1 \mathrm{~mm}$ ) foram utilizados como superfície de contato para a formação dos biofilmes.

\section{Curva de calibração}

Primeiramente foi obtida a curva de calibração das bactérias, sendo que estas foram ativadas em ágar nutriente - AN (HIMEDIA, China) e incubadas por $24 \mathrm{~h} / 36{ }^{\circ} \mathrm{C}$. Após as $24 \mathrm{~h}$ transferiram-se algumas alçadas para o meio caldo triptona de soja - TSB (HIMEDIA, China) e este foi incubado $16-18$ horas à $36^{\circ} \mathrm{C}$. Realizaram-se diluições seriadas $(500 \mu \mathrm{L}$ de suspensão bacteriana e $500 \mu \mathrm{L}$ de meio TSB). Dessas diluições foi transferido $200 \mu \mathrm{L}$ para placas de 96 poços para realização de leitura em espectrofotômetro ELISA (BIOTEK, USA).

De cada diluição acima, foi retirada uma alíquota de $100 \mu \mathrm{L}$ e foi transferida a um erlenmeyer contendo $900 \mu \mathrm{L}$ de água peptonada (HIMEDIA, China), realizando nova diluição seriada. Posteriormente, através da técnica de microgota, alíquotas de $0,1 \mathrm{~mL}$ foram retiradas de cada diluição e transferidas para superfície de ágar triptona de soja - TSA 
(HIMEDIA, China). Após 24 h de incubação à $36^{\circ} \mathrm{C}$, realizou-se a contagem das células viáveis. Tabularam-se os dados obtendo-se uma linha de tendência linear de modo que o $\mathrm{R}^{2}$ se encontrasse acima de 0,91 , partindo do conceito que uma linha de tendência é mais confiável quando o valor de $\mathrm{R}^{2}$ esta em ou próximo de 1.

\section{Higienização dos cupons}

O protocolo para a higienização dos cupons foi realizado de acordo com o descrito por Millezi et al. (2012). Os cupons foram esterilizados em autoclave a $121{ }^{\circ} \mathrm{C} / 15 \mathrm{~min}$, imersos em $0,3 \%$ de ácido acético em água destilada estéril e, por fim, auto clavados novamente.

\section{Adesão das células bacterianas}

Para a formação de biofilme foi realizada a padronização dos inóculos em aproximadamente $10^{8} \mathrm{UFC} / \mathrm{mL}$ (mediante curva de calibração). Em recipientes separados, contendo $250 \mathrm{~mL}$ de meio caldo triptona de soja - TSB (HIMEDIA, China), adicionouse o inóculo padronizado e introduziram-se 2 cupons de cada superfície (aço e polipropileno), mantidos em suspensão por fios metálicos em aço inoxidável estéreis. Depois de lacrados, os sistemas foram introduzidos em shake orbital (Tecnal, Brasil) por $24 \mathrm{~h}$ a $37{ }^{\circ} \mathrm{C}$ com agitação constante de $110 \mathrm{rpm}$ (MILLEZI et al., 2012).

\section{Enumeração das células bacterianas aderidas}

A quantificação das células viáveis em biofilmes foi realizada de acordo com Milleziet al. (2012). Após as 24 h, os cupons foram coletados. As células sésseis foram removidas da superfície dos cupons em 6 min de banho ultrassom (UNIQUE, Brasil).
Retirou-se $0,1 \mathrm{~mL}$ e transferiu-se para microtubos contendo $0,9 \mathrm{~mL}$ de água peptonada. Procedeu-se a agitação em vórtex e diluição seriada das amostras. Posteriormente, através da técnica de microgota, alíquotas de $0,1 \mathrm{~mL}$ foram retiradas de cada diluição e plaqueadas em superfície de ágar triptona de soja - TSA (HIMEDIA, China). Após $24 \mathrm{~h}$ de incubação à $36^{\circ} \mathrm{C}$, realizou-se a contagem das células viáveis em biofilmes.

\section{Quantificação da biomassa}

A biomassa dos biofilmes foi quantificada pela técnica do cristal violeta de acordo com Stepanovicetal. (2000). Este método tem a propriedade de mensurar a quantidade de biomassa formada (matriz de polissacarídeos). As células aderidas foram fixadas das com metanol 99\% (5 min), coradas com cristal violeta (5 $\mathrm{min})$, lavadas em água destilada e, por fim, adicionou-se $1 \mathrm{~mL}$ de ácido acético $33 \%$ para leitura a $630 \mathrm{~nm}$ em espectrofotômetro ELISA (BIOTEK, USA).

\section{Microscopia eletrônica de varredura}

A obtenção das eletromicrografias dos microrganismos aderidos à superfície de polipropileno e aço inoxidável AISI 304 foi realizada de acordo com Alves (2004). Utilizou-se o microscópio eletrônico de varredura LEVO EVO 40 XVP scanning eléctron microscope, marca Zeiss.

\section{Análise estatística}

O experimento foi delineado com três repetições. Os dados foram submetidos a análise de variância (ANOVA), utilizando nível de significância de 0,01. O teste estatístico aplicado foi o Bonferroni, realizado através do software Prisma (Graf Pad Software). 


\section{RESULTADOS E DISCUSSÃO}

Conforme a Figura 1, a maior contagem de células viáveis em biofilme ocorreu para $P$. aeruginosa $\left(7,34 \log 10 \mathrm{UFC} / \mathrm{cm}^{2}\right.$ em aço e 7,32 log $10 \mathrm{UFC} / \mathrm{cm}^{2}$ em polipropileno) e $S$. Typhimurium $\left(6,69 \log 10 \mathrm{UFC} / \mathrm{cm}^{2}\right.$ em aço e 7,16 log $10 \mathrm{UFC} / \mathrm{cm}^{2}$ em polipropileno). Estatisticamente, não houve diferença entre as contagens das células de $P$. aeruginosa e $S$. Typhimurium $(\mathrm{p}>0,05)$.

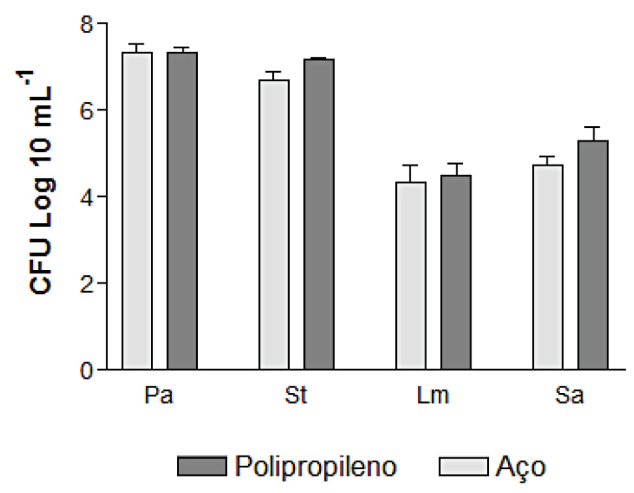

Figura 1 - Células bacterianas viáveis em biofilme nas superfícies de aço inoxidável e polipropileno. Pa: $P$. aeruginosa; St: $S$. Typhimurium; Lm: L. monocytogenes; Sa: S. aureus

Contudo, contagens inferiores foram obtidas para L. monocytogenes (4,33 log 10 $\mathrm{UFC} / \mathrm{cm}^{2}$ em aço e 4,49 $\log 10 \mathrm{UFC} / \mathrm{cm}^{2}$ em polipropileno) e $S$. aureus $(4,75 \log 10$ $\mathrm{UFC} / \mathrm{cm}^{2}$ em aço e 5,30 $\log 10 \mathrm{UFC} / \mathrm{cm}^{2} \mathrm{em}$ polipropileno). Estatisticamente, não houve diferença entre as contagens das células entre L. monocytogenes e $S$. aureus.

Verificou-se que todas as outras comparações são significativas $(\mathrm{p}<0,05)$, ou seja, a formação de biofilme de $P$. aeruginosa foi significativamente maior que $L$. monocytogenes e $S$. aureus, assim como a formação de biofilme de $S$. Typhimurium também foi significativamente maior que $L$. monocytogenes e $S$. aureus (estatística semelhante para ambas às superfícies testadas - aço e polipropileno). P. aeruginosa destaca-se neste estudo, como a maior formadora de células viáveis em biofilme. Em pesquisa de Caixeta (2008), para superfície de aço inoxidável na presença do leite desnatado como substrato, observou também ótimo crescimento de $P$. aeruginosa, apresentando 10,4 Log UFC/mL.

$\mathrm{O}$ número de microrganismos presentes na superfície é um parâmetro que determina se há a formação de biofilme maduro ou somente adesão bacteriana. Segundo Andrade et al. (1998), para se considerar um biofilme, é necessário um número mínimo de $7 \mathrm{Log} 10 \mathrm{UFC} / \mathrm{cm}^{2}$, enquanto Ronner e Wong (1993) e Wirtanen et al. (1996) consideram respectivamente, $5 \mathrm{Log} 10 \mathrm{UFC} / \mathrm{cm}^{2}$ e $3 \mathrm{Log} U F C / \mathrm{cm}^{2}$. Em comparação com o resultado obtido neste estudo, salienta-se que os números de células microbianas aderidas de todas as espécies bacterianas testadas encontravam-se na faixa de biofilme maduro. Um biofilme maduro pode levar de algumas horas até várias semanas para desenvolverse, dependendo das condições de seu meio ambiente. Sendo assim, existem na literatura teorias propostas para formação de biofilmes (IST, 2005; MEDONLINE, 2016).

Quanto à produção de biomassa, $P$. aeruginosa apresentou-se superioras demais espécies bacterianas deste estudo, exibindo leitura de 1.48 para aço e 1.54 para polipropileno, confirmado dados da literatura que descrevem essa bactéria como uma forte formadora de biofilme. S. enteritidis, $S$. aureus e L. monocytogenes produziram respectivamente, $0.072,0.094$ e 0.075 para aço e $0.099,0.077$ e 0.104 para polipropileno. Sendo assim, as demais bactérias produziram pouca biomassa, sendo essas significativamente inferiores em comparação a $P$. aeruginosa, como pode ser observado na Figura 2. 


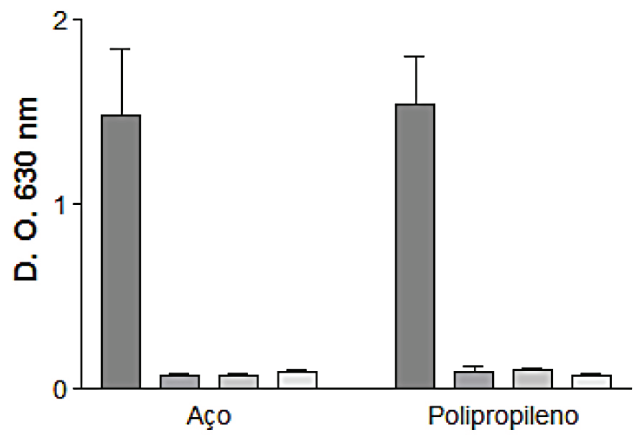

$\square$ Salmonella Enteritidis

$\square$ Pseudomonas aeruginosa

Listeria monocytogenes

Staphylococcus aureus

Figura 2 - Biomassa de biofilme bacteriano nas superfícies de aço inoxidável e polipropileno

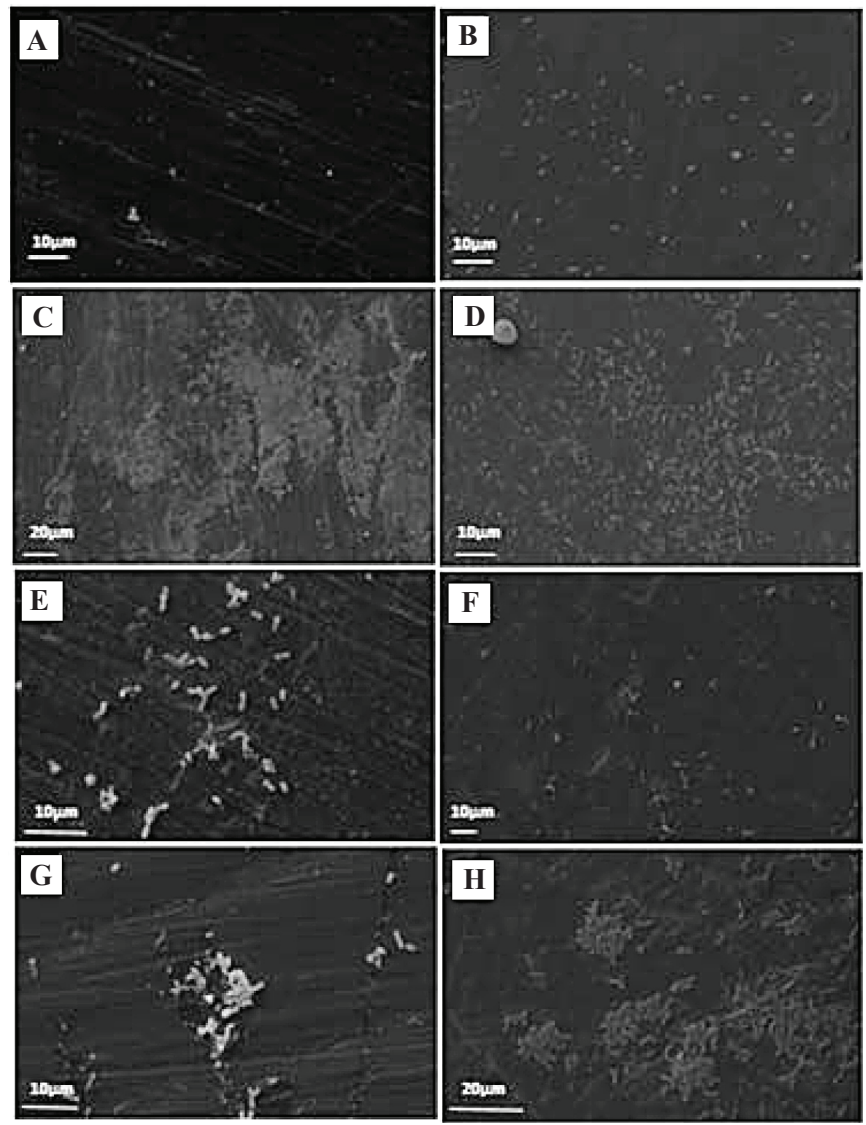

Figura 3 - Microscopia eletrônica de varredura das espécies bacterianas. A: Listeria monocytogenes (aço); B: L. monocytogenes (polipropileno); C: Pseudo monasaerugnosa (aço); D: P. aeruginosa (polipropileno); E: Staphylococcus aureus (aço); F: S. aureus (polipropileno); G: Salmonella Typhimurium (aço); H: S. Typhimurium (polipropileno) 
Analisando os resultados obtidos para o método visual de microscopia eletrônica de varredura, percebe-se que a bactéria $P$. aeruginosa aderiu-se em maiores quantidade sem comparação as outras espécies bacterianas testadas para ambas às superfícies (aço inoxidável e polipropileno), conforme ilustrado na Figura 3.

Comparando os métodos de quantificação de biofilmes não visuais (quantificação de células viáveis em biofilme e biomassa) com o método visual (microscopia eletrônica de varredura), nota-se eficiência da adesão microbiana para a espécie $P$. aeruginosa.

Visto os dados obtidos, destaca-se preocupação devido a grande capacidade de adesão de $P$. aeruginosa em condições favoráveis para seu crescimento. Contudo, observa-se que mesmo em baixíssimas concentrações de matéria orgânica, é possível permitir o crescimento e reprodução de $P$. aeruginosa, indicando desta forma seu potencial para o desenvolvimento de biofilme até mesmo em condições limitadas em termos de nutrientes (MEDONLINE, 2016).

\section{CONCLUSÕES}

Pode-se observar que as espécies bacterianas estudadas possuem capacidade de aderência em superfícies usadas nas indústrias de alimentos (aço inoxidável e polipropileno), com perspectiva de causar problemas nesses ambientes, principalmente à espécie $P$. aeruginosa. Destaca-se a importância de estudos futuros a fim minimizar o risco de adesão microbiana e desta forma evitar possível contaminação durante o processamento de alimentos.

\section{REFERÊNCIAS}

\author{
ALVES, E. Introdução à microscopia \\ eletrônica de varredura e de transmissão. \\ Lavras: UFLA-FAEPE, 2004. 43 p.
}

ANDRADE, N. J.; BRIDGEMAN, T. A.;ZOTTOLA, E. A. Bacteriocidal activity ofsanitizers against Enterococcus faecium attached to stainless steel as determined byplate count and impedance methods. Journal of Food Protection, v. 61, n. 7, p. 833-838, 1998.

\section{CAIXETA, D. S. Sanificantes químicos no controle de biofilmes formados por duas espécies de Pseudomonas em superfície de aço inoxidável. 2008.86p. Dissertação (Mes- trado em Microbiologia Agrícola) - Uni- versidade Federal de Lavras, Lavras, 2008. \\ CRIADO, M. T.; SUÁREZ, B.; FERRERÓS, C. M.The importance of bacterial adhesion in dairy industry. Food Technology. v. 48, n. 2, p. 123-126, 1994.}

DUNNE JÚNIOR, W. M. Bacterial adhesion: Seen any good biofilms latety? Clinical Microbiology, Whashington, v. 15, n. 2, p. 155-166, 2002.

IST. Grupo de Ciências Biológicas do Instituto Superior Técnico. Universidade Técnica de Lisboa. Crescimento microbiano em biofilmes. Disponível em: <http:// e-escola.tecnico.ulisboa.pt/topico.asp? $\mathrm{id}=354 \&$ ordem $=2>$. Publicado em: 18 nov. 2005. Acesso em: 27 mar. 2017.

KINGSHOTT, J. et al. Covalent attachment of poly (ethylene glycol) to surfaces, critical for reducing bacterial adhesion. Langmuir, v. 19, n. 17, p. 6912-6921, 2003.

KIVES, J.; ORGAZ, B.; SANJOSE, C. Polysacharide differences between planktonic and biofilm-associated EPS from Pseudomonas fluorescens B52. Colloids and Surfaces B: Biointerfaces, n. 52, p. 123-127, 2006.

LERICHE, V.; CARPENTIER, B. Viable 
but non culturable Salmonella typhymurium in single and binary biofilms in response to chlorine treatment. Journal of Food Protection, v. 58, p. 1186-1191, 1995.

MAH, T. F. C.; O’TOOLE, G. A. Mechanisms of biofilm resistence to antimicrobial agents. Trends in Microbiology, v. 9, n. 1, p. 34-39, 2001.

MEDONLINE. Medicina Online. Biofilme: um velho problema, uma nova batalha. Revista Virtual de Medicina. Disponível em: $<$ http://www.medonline.com.br/> Acesso em: 19 jan. 2016.

MILLEZI, F. M.; et al. Susceptibility of mono species and dual-species biofilms of Staphylococcus aureus and Escherichia coli to essential oils. Journal of Food Safety, v. 32, n. 3, p. 351-359, 2012.

PARIZZI, S. Q. F. et al. Bacterial adherence to different inert surfaces evaluated by epifluorescence microscopy and plate count method. Brazilian Archives of Biology Technology, v. 47, n. 1, p. 77-83, 2004.
RONNER, A. B.; WONG, A. C. L. Biofilm development and sanitizer inactivation of Listeria monocytogenes and Salmonella Typhimuriumon stainless steel and buna-n rubber. Journal of food Protection, v. 56, n. 9 , p. 750-758, 1993.

SHARMA, M.; ANANND, S. K. Characterization of constitutive microflora of biofilms in dairy processing lines. Food Microbiology, v. 19, n. 6, p. 627-636, 2002.

SMITH, J. L.; FRATÂMICO, P. M., Factors involved in the emergence and persistence of foodborne diseases. Journal of Food Protection, v. 58, n. 6, p. 696-708, 1995.

STEPANOVIC, S. et al. A modified microtiter-pate test for quantification of staphylococcal biofilm formation. Journal of Microbiology and Methods. v. 40, p. 175-179, 2000 .

WIRTANEN, G. et al. Microbial evaluation of the bio transfer potencial from surfaces with Bacillus biofilms after rinsing and cleaning procedures in closed food-processing systems. Journal of Food Protection, v. 59, n. 7, p. 727-733, 1996. 